\title{
Assessing Pulmonary Pathology by Detailed Examination of Respiratory Function
}

Louis J. Vaickus, Jacqueline Bouchard, Jiyoun Kim, Sudha Natarajan, and Daniel G. Remick

From the Department of Pathology, Boston University School of Medicine, Boston, Massachusetts

Pulmonary inflammation causes multiple alterations within the lung, including mucus production, recruitment of inflammatory cells, and airway hyperreactivity (AHR). Measurement of AHR by direct, invasive means (eg, mechanical ventilation) or noninvasive techniques, like whole body plethysmography (WBP), assesses the severity of pulmonary inflammation in animal models of inflammatory lung disease. Direct measurement of AHR is acknowledged as the most accurate method for assessing airway mechanics, but analysis of all data obtained from WBP may offer insights into which inflammatory aspects of the lung are altered along with AHR. Using WBP, we compared the respiratory parameters of two groups of mice sensitized with cockroach allergen. One group was treated with dexamethasone (Dex) before final challenge (DexAsthma), while the other group received vehicle treatment (Asthma). Respiratory parameters from plethysmography revealed that Dex-Asthma mice compensated to maintain high minute ventilation, whereas Asthma mice showed significant impairment in minute ventilation despite increased peak expiratory flow $(103 \pm 5 \mathrm{ml} / \mathrm{min}$ vs. $69 \pm 70 \mathrm{ml} /$ min). The WBP data suggest that enhanced air exchange in the Dex-Asthma mice results from significant decreases in airway mucus production. Additional studies with quantitative morphometry of histological sections confirmed that Dex reduced airway mucus. In conclusion, a detailed examination of WBP parameters can accurately assess the respiratory health of mice and will help direct additional studies. (Am J Pathol 2010, 177:1861-1869; DOI: 10.2353/ajpath.2010.100053)

Numerous relevant animal models of disease have advanced the understanding of biology and provided im- portant insights into the pathogenesis of human disease. The vast majority of these studies have been carried out in mice, due to their small size and the extensive characterization of the murine inflammatory system. Several robust murine models of allergic asthma have been developed in recent years, ${ }^{1}$ including many experimental systems which induce allergic sensitization to ovalbumin (Ova). Although this system allows close control over the nature of the sensitizing agent, Ova is a relatively poor allergen and requires adjuvant co-administration or relatively high and frequent doses to achieve satisfactory immunization. ${ }^{2-5}$ Our model, conversely, uses an allergen composed of the defatted, total body extract of German cockroaches (cockroach allergen, CRA) containing appreciable lipopolysaccharide. CRA is a highly potent allergen (robust immunization is achieved with a dose thousands of times less than that required for Ova) and does not require an adjuvant for sensitization. ${ }^{6,7}$ Campbell et $\mathrm{al}^{7}$ established the first CRA induced model of asthma in mice and demonstrated robust pulmonary inflammation with many asthma-like features. The complex nature of this allergen and its close correspondence with its urban environmental counterpart makes this model highly applicable to the study of human disease.

In most models of allergic airways inflammation, disease severity and or therapeutic efficacy is evaluated via measuring multiple parameters including airways hyperreactivity (AHR) in response to methacholine, cytokine and chemokine concentrations in bronchoalveolar lavage (BAL) and lung homogenates, lung inflammatory cell infiltrates and lung histological changes. ${ }^{8-10}$ AHR is typically addressed via direct (forced oscillation) or indirect (whole body plethysmography, WBP) methods. Direct measurement of lung resistance, elastance and compliance by forced oscillation is the gold standard for the evaluation of AHR. Unfortunately, this procedure requires

Supported by National Institute of Environmental Health Sciences (NIEHS) grant 5R01ES013538-04.

Accepted for publication June 18, 2010.

Supplemental material for this article can be found on http://ajp. amjpathol.org.

Address reprint requests to Daniel G. Remick, M.D., Department of Pathology, Boston University School of Medicine, $4^{\text {th }}$ Floor, 670 Albany St, Boston, MA 02118. E-mail: remickd@bu.edu. 
direct, tracheal cannulation in anesthetized mice and is typically terminal.

WBP has become widely used due to its ease of use and ability to make multiple measurements on mice without inducing significant injury or distress. ${ }^{2,11,12}$ This method of AHR evaluation employs the composite parameter known as enhanced pause (Penh) which is correlated with but not a direct measurement of resistance. ${ }^{13-15}$ WBP has the advantage of being performed on awake, unrestrained mice in a nonterminal fashion, allowing for repeated measurements. ${ }^{15-17}$ However, the relationship of Penh to direct resistance is hotly debated and many editorials question the utility of WBP. ${ }^{18-21}$ If the primary goal of a study is to evaluate lung resistance forced oscillation experiments are almost certainly necessary.

The following research examines whether respiratory parameters other than Penh which are measured by WBP can provide insight into the overall pulmonary health of the experimental animals. In the current studies several Penh-related and -unrelated parameters were examined to determine whether individual measurements provided information concerning the pulmonary health of mice. Additionally, we sought to use WBP to derive insight to target studies to the mechanisms of pulmonary derangements. We hypothesize that dexamethasone treatment before the final allergen challenge will lead to significant changes in WBP respiratory parameters and that these will correlate with alterations in the inflammatory profile of the DEX-treated mice.

\section{Materials and Methods}

Allergen sensitization: CRA was purchased from Greer Laboratories (Lenoir, NC) as a lyophilized whole body extract of the German cockroach Blattella germanica. The CRA was reconstituted in sterile PBS and the concentration of components Blag1 and Blag2 were assayed by enzyme-linked immunosorbent assay. The concentration of the solution was adjusted so that $50 \mu \mathrm{l}$ will contain $8 \mu \mathrm{g}$ of combined Blag1 and Blag2. The immunization (day 0) and 2 challenges (days 14 and 21) were delivered intratracheally by direct pharyngeal delivery which is subsequently inhaled. ${ }^{22}$ The mouse was suspended by its front incisors on an incline board, its tongue was gently pulled forward and the CRA solution was placed at the back of the pharynx in two $25 \mu \mathrm{l}$ aliquots for aspiration. The immunization dose was a 1:2 dilution of the stock solution and the challenges were a 1:4 dilution containing $4 \mu \mathrm{g}$ and $2 \mu \mathrm{g}$ combined Blag1 and Blag2 respectively.

Dexamethasone and vehicle treatment: The DexNaïve and Dex-Asthma mice were given two intraperitoneal injections of $2.5 \mathrm{mg} / \mathrm{kg}$ of water soluble dexamethasone in $100 \mu$ l of sterile water. In the Dex-Asthma group the injections were delivered 2 hours before final challenge (26 hours before AHR measurement) and given again 2 hours before AHR measurement and sacrifice. In the Dex-Naïve mice the injections were administered 26 hours and 2 hours prior AHR measurement and sacrifice. The Asthma mice received two injections of $100 \mu$ l of sterile water on the same time schedule as the Dex-Asthma mice.

Respiratory measurements: 24 hours following the final challenge the Dex-Asthma and Asthma mice were placed in unrestrained whole body plethysmograph chambers and exposed to a 2 minute aerosolization of PBS, $25 \mathrm{mg} / \mathrm{ml}$ or 50 $\mathrm{mg} / \mathrm{ml}$ methacholine followed by a 5 minute recording period (Buxco Research Systems, Wilmington, NC). The Naïve mice were allowed to acclimate to the animal facility for 1 week and then were evaluated by WBP at the same time of day as the other groups of mice. The Dex-Naïve mice were allowed to acclimate to the mouse facilities before DEX injections and AHR measurement. All respiratory parameters are collected simultaneously by the WBP instrument. All factors are recorded and exported automatically with no supervised manipulation.

Sacrifice and data collection: The mice were anesthetized with ketamine/xylazine via i.p. injection and then sacrificed by exsanguination and cervical dislocation. The trachea was opened and cannulated with a length of flexible tube and the lungs were lavaged with $2 \mathrm{ml}$ of warm Hank's buffered salt solution in $250 \mu$ aliquots. The lungs were removed and fixed in $70 \%$ ethanol for histology. The lavage fluid was centrifuged at $600 \times g$ for 5 minutes and the supernatant was removed. The cell pellet was resuspended in $200 \mu$ l of RPMI buffer, and the red cells were lysed and counted on Coulter particle counter (Beckman Coulter, Fullerton CA). The cells were then adhered to a slide and counted at $\times 1000$ magnification. The absolute cell counts per BAL sample were calculated for total white cells, neutrophils, macrophages, eosinophils, and lymphocytes.

Histology: The right lung was removed from fixative and cut coronally through the midline with a razor blade. The top half of each lung was sent to the Boston University Pathology Core Services where it was paraffin embedded, sectioned, and stained with Periodic Acid Schiff (PAS) for mucus analysis. PAS quantization was performed on $\times 2$ digital images of the entire lung section using ImageJ (http://rsbweb.nih.gov/ij/). Briefly the background of the image was subtracted and the image was color deconvoluted. The red portion of the image was selected and the intensity was adjusted in the same manner for each image. This image was converted to black and white and the total black (PAS-stained) area of the image was calculated.

Microarray software analysis: Microarray analysis was performed using freeware TM4-MEV software. Data were first subjected to Z-score normalization so that parameters with vastly different ranges may be directly compared. Briefly the average and SD of the data for each parameter was calculated across groups. The Z-score was then calculated as the average for each data group subtracted from each data point and the difference divided by the SD for each data group (X-Avg)/ $\mathrm{SD}$. The heat map software is freely available at http://www.tm4.org/mev.html.

Statistical analysis: Analysis of respiratory parameters was performed by two-way analysis of variance with Bonferoni post test comparing all groups. Statistical analysis of BAL cells and airways mucuswas performed by one- 
way analysis of variance with Bonferoni post test. Raw data concerning all comparisons detailed in the results section can be found in Supplemental Table 1, at $h$ ttp:// ajp.amjpathol.org. All calculations were carried out in Graphpad Prism 4.0 (La Jolla, CA).

\section{Results}

\section{Respiratory Parameters}

Comparison by one-way analysis of variance of the data from Naïve and Dex-Naïve mice (Naïve mice given two injections of DEX on the same time intervals as the DexAsthma mice) revealed no significant differences between these two groups in any of the measured parameters (data not shown). Accordingly, the groups were merged into a single group listed as Naive. In our experiments, the respiratory rate in ICR mice ranges from 300 to 400 breaths per minute in healthy mice to a lower limit of roughly 100 breaths per minute in the most severe cases of pulmonary inflammation. The respiratory rates (RR) of Naïve, Asthma and Dex-Asthma mice were recorded following exposure to 2 minutes of nebulization of PBS, $25 \mathrm{mg} / \mathrm{ml}$ or $50 \mathrm{mg} / \mathrm{ml}$ methacholine (Mch) (Figure 1A). The Naîve group showed moderate decreases in respiratory rate with exposure to methacholine, but these changes were not statistically significant. In contrast, the respiratory rates of Asthma and Dex-Asthma mice showed dose dependent decreases in RR with increasing methacholine exposure. At $25 \mathrm{mg} / \mathrm{ml}$ of methacholine, both the Asthma and Dex-Asthma groups showed significantly decreased RR compared to Naïve. At $50 \mathrm{mg} / \mathrm{ml}$ of methacholine, the Asthma and Dex-Asthma groups exhibited further decreases in RR as compared to their Naïve counterparts.

Tidal volume in mice is usually maintained at approximately $200 \mu \mathrm{l}$ in comfortable healthy animals. ${ }^{23,24}$ On methacholine exposure allergen sensitized and challenged mice will typically elevate their TV to compensate for dyspnea due to increased pulmonary distress. Without the methacholine challenge, the tidal volume was nearly identical in all three groups of mice, indicating that while the mice have pulmonary inflammation it would not be considered an acute exacerbation (ie, status asthmaticus). The tidal volume (TV) of Naïve mice did not respond to the lower dose of methacholine but showed a significant elevation at $50 \mathrm{mg} / \mathrm{ml}$ of methacholine (Figure 1B, complete statistical analysis provided in Supplemental Table S1, http://ajp.amjpathol.org.). The TV values of Asthma and Dex-Asthma groups showed significant elevation in response to both $25 \mathrm{mg} / \mathrm{ml}$ and $50 \mathrm{mg} / \mathrm{ml}$ of Mch as compared to Naive. At the higher dose of methacholine the TV of the Dex-Asthma mice significantly exceeded that of the Asthma mice.

Minute ventilation (MV) is the product of RR and TV and represents the $\mathrm{ml}$ of air exchanged each minute. The MV of Naïve mice was not significantly altered by exposure to $25 \mathrm{mg} / \mathrm{ml}$ of methacholine but was elevated by the higher dose (Figure 2). Allergen sensitized and challenged mice make an effort to elevate their TV or RR, or both suggest-

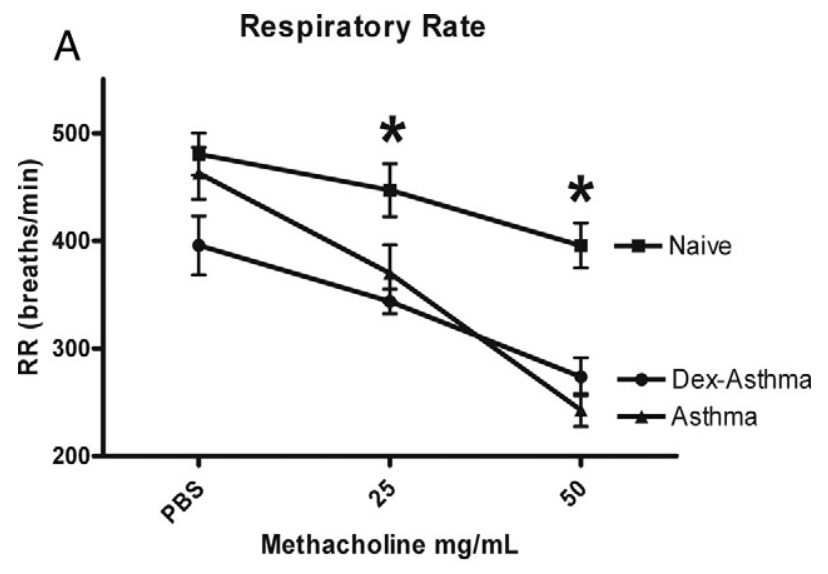

B Tidal Volume

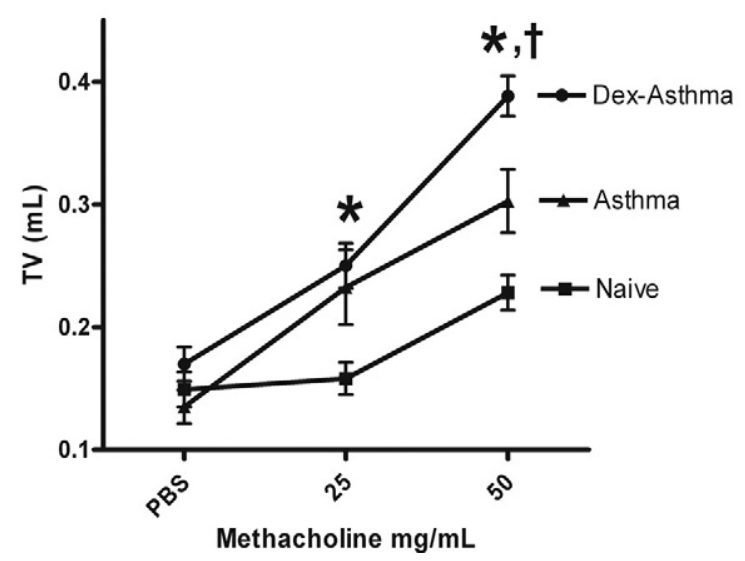

Figure 1. Respiratory rate (RR) and tidal volume (TV). Respiratory rate was measured breath for breath over the methacholine exposure period of 5 minutes. The collected values are averaged over the exposure period in units of breaths/minute $(\mathbf{A})$. Tidal volume reflects the amount of air exchanged per breath in $\mathrm{ml}(\mathbf{B})$. Each value is the mean \pm SEM for $n=8 .{ }^{*} P<0.05$ comparing both Asthma and Dex-Asthma to Naïve and ${ }^{\dagger} P<0.05$ for Asthma compared to Dex-Asthma by two-way analysis of variance with Bonferroni's post test. Both Asthma and Dex-Asthma mice showed significantly reduced RR compared to Naïve mice at increasing doses of methacholine. The DexAsthma mice exhibited significantly increased TV at $50 \mathrm{mg} / \mathrm{ml}$ methacholine compared to both Naïve and Asthma groups of mice.

ing that they are attempting to maintain or elevate MV. In the most severe cases of pulmonary inflammation, mice cannot increase RR or TV and their MV declines. The Asthma mice elevated their minute ventilation above PBS challenge levels in response to $25 \mathrm{mg} / \mathrm{ml}$ of methacholine but were not able to raise MV any further to compensate for the higher Mch dose and actually showed a decrease in MV compared to at $25 \mathrm{mg} / \mathrm{ml}$ of methacholine. Conversely, the Dex-Asthma mice elevated their MV in response to 25 and $50 \mathrm{mg} / \mathrm{ml}$ of Mch as compared to PBS. Additionally, the MV of the Dex-Asthma mice in response to the higher Mch dose meaningfully exceeded that of the Asthma mice.

The time of inspiration and peak inspiratory flow of the Naîve mice did not change significantly in response to methacholine (Figure 3, A and B). In allergen sensitized and challenged mice $\mathrm{Ti}$ and PIF are primarily influenced by extrapleural obstructions and are typically elevated with Mch challenge when an obstruction exists. ${ }^{25,26}$ The Asthma and Dex-Asthma mice showed 


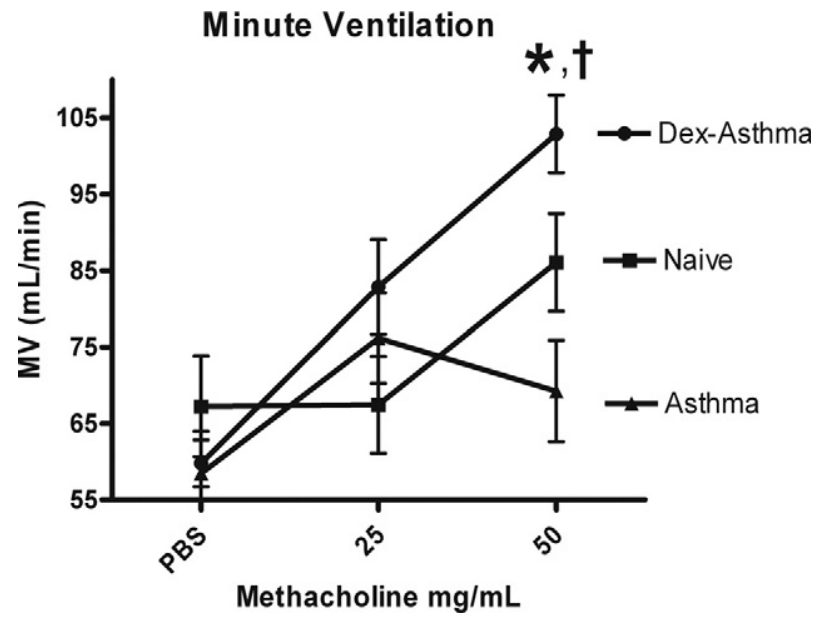

Figure 2. Minute Ventilation (MV). Minute ventilation is the product of RR and TV and indicates the volume of air exchanged in 1 minute in units of $\mathrm{ml} / \mathrm{min}$. Each value is the mean \pm SEM for $n=8 .{ }^{*} P<0.05$ for both Asthma and Dex-Asthma compared to Naïve. ${ }^{\dagger} P<0.05$ for Dex-Asthma compared to Asthma. The Dex-Asthma group of mice showed significantly elevated MV at $50 \mathrm{mg} / \mathrm{ml}$ methacholine compared to the Naïve and Asthma groups of mice.

slight increases in Ti in response to the lower dose of Mch and significantly elevated $\mathrm{Ti}$ at the higher dose as compared to Naïve. The peak Ti and PIF values of the Asthma and Dex-Asthma mice were not meaningfully different from each other.

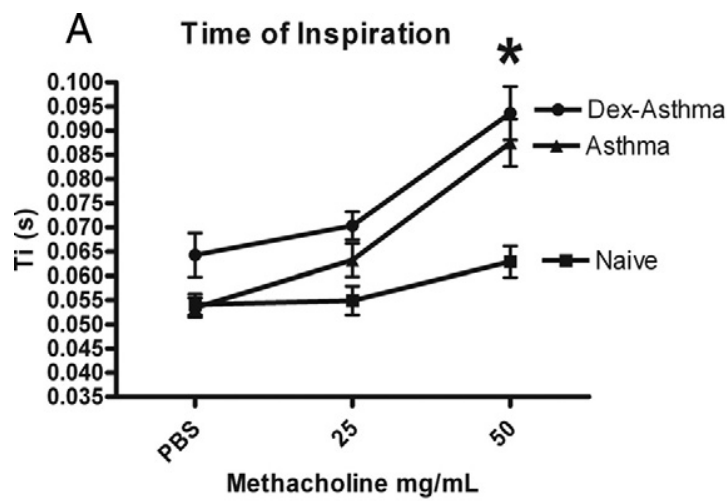

\section{B Peak Inspiratory Flow}

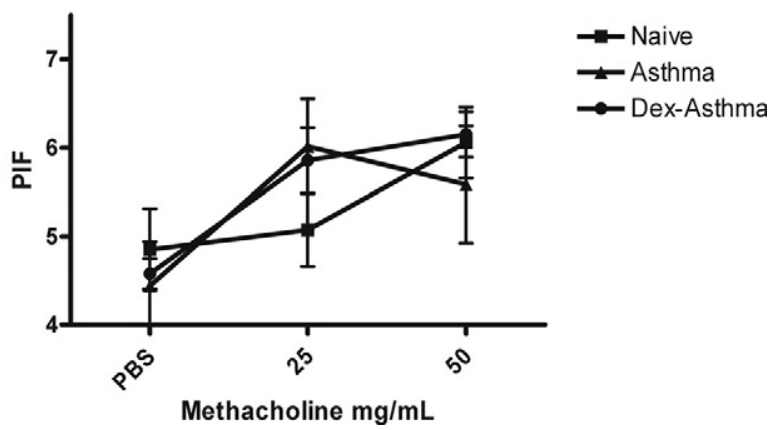

Figure 3. Time of inspiration and peak inspiratory flow rate. Time of inspiration $(\mathbf{A})$ is measured in seconds and indicates the period from initiation of inspiration to end inspiration. Peak inspiratory flow (B) is measured in $\mathrm{ml} / \mathrm{s}$ and indicates the maximum inspiratory flow rate. Each value is the mean \pm SEM for $n=8$. ${ }^{*} P<0.05$ for both Asthma and Dex-Asthma compared to Naïve. The Asthma and Dex-Asthma mice exhibited elevated Ti compared to the Naïve mice at the higher dose of methacholine. There were no significant differences in the PIF values as any of the methacholine doses.
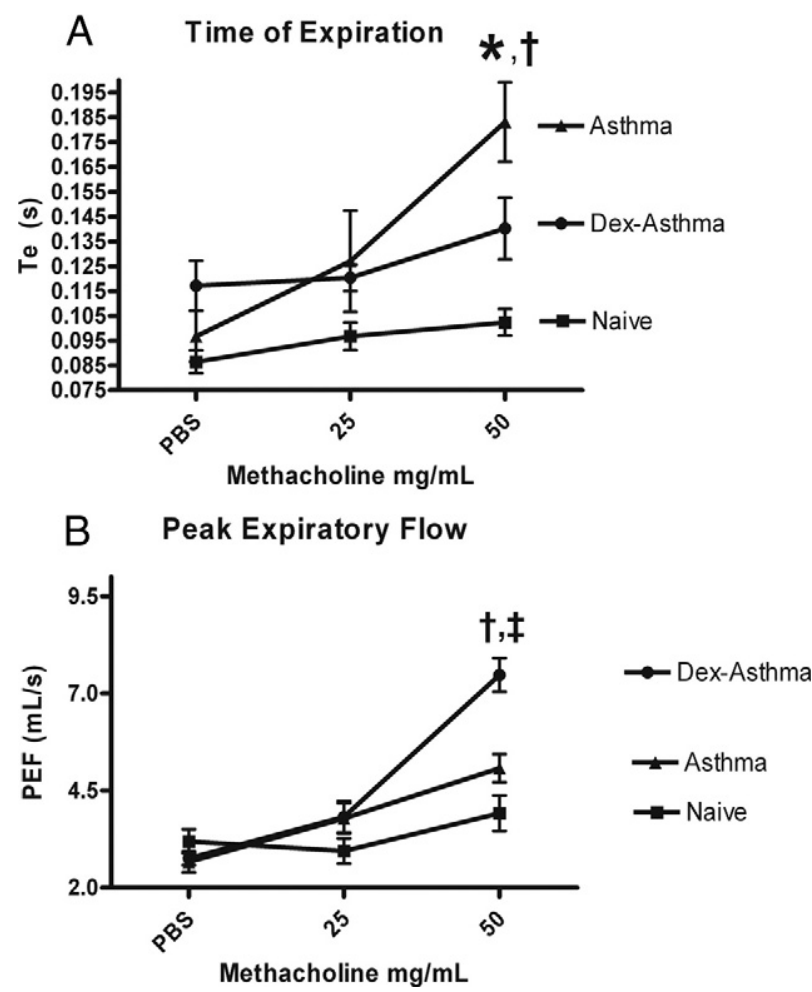

Figure 4. Time of expiration and peak expiratory flow rate. Time of expiration (A) is the time in seconds from the initiation of expiration to end expiration. Peak expiratory flow $(\mathbf{B})$ is the maximum flow rate during expiration measured in $\mathrm{ml} / \mathrm{s}$. Each value is the mean \pm SEM for $n=8{ }^{*} P<0.05$ for both Asthma and Dex-Asthma compared to Naïve. ${ }^{\dagger} P<0.05$ for DexAsthma compared to Asthma. ${ }^{\ddagger} P<0.05$ for Dex-Asthma compared to Naïve. Both Asthma and Dex-Asthma mice had significantly elevated times of expiration compared to Naive at the higher dose of methacholine. The Asthma mice also had a meaningfully higher Te at $50 \mathrm{mg} / \mathrm{ml}$ o methacholine compared to the Dex-Asthma mice. The Dex-Asthma mice had significantly increased PEF as compared to both Naïve and Asthma groups of mice.

Time of expiration and peak expiratory flow rate are strongly affected by intrapleural airways obstructions. $^{27,28}$ The Te and PEF of the Naïve mice were not significantly increased by either dose of Mch (Figure 4, A and $\mathrm{B}$ ). The $\mathrm{Te}$ of the Asthma mice was significantly elevated as compared to Naïve and Dex-Asthma mice at the higher dose of Mch. Conversely, the Dex-Asthma mice had a slightly elevated Te with PBS challenge as compared to Naïve and Dex-Naïve, but their Te did not increase significantly in response to Mch. Additionally, the PEF of the Dex-Asthma mice at the higher dose of methacholine was significantly higher than that of the Asthma mice.

Penh is a composite, dimensionless value which can be used to screen experimental animals for pulmonary distress and Mch hypersensitivity. Penh = PEF/PIF * Te/RT - 1. Increases in Penh reflect elevations in Te and PEF and decreases in PIF and relaxation time (RT). The Penh of the Naïve mice was not significantly altered by either of the doses of methacholine (Figure 5). Both the Asthma and Dex-Asthma mice show slight increases in Penh in response to $25 \mathrm{mg} / \mathrm{ml}$ of Mch and a threefold increase in Penh at the higher dose of Mch. Interestingly, the Penh responses of the Asthma and Dex-Asthma did not differ significantly. 


\section{Enhanced Pause (Penh)}

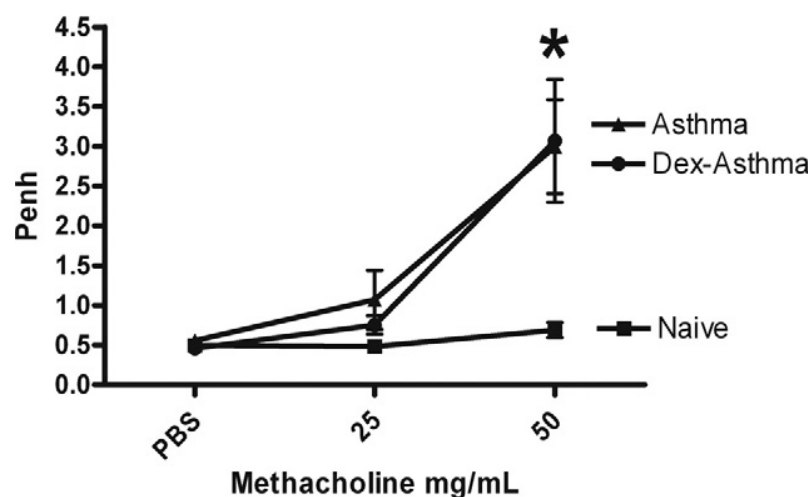

Figure 5. Enhanced pause (Penh). Penh is a dimensionless composite value $=(\mathrm{PEF} / \mathrm{PIF}) *(\mathrm{Te} / \mathrm{RT})-1$. Each value is the mean \pm SEM for $n=8$ ${ }^{*} P<0.05$ for both Asthma and Dex-Asthma compared to Naïve. The Asthma and Dex-Asthma mice had significantly increased Penh at $50 \mathrm{mg} / \mathrm{ml} \mathrm{metha-}$ choline compared to the Naïve group of mice.

\section{BAL Inflammatory Cells}

Inflammatory cells were isolated from the BAL fluid of the Naîve, Asthma, and Dex-Asthma mice to determine the impact of allergic sensitization to CRA. In the Naïve mice, BAL neutrophils (PMN), eosinophils, and lymphocytes were extremely rare (Figure 6). Numbers of macrophages were not significantly different in any mouse group (Figure 6A). Elevated neutrophils were present in both the Asthma and Dex-Asthma mice (Figure 6B), showing that DEX did not alter the number of pulmonary PMNs. In the Asthma mice there was a significant increase in both lymphocytes (Figure 6C) and eosinophils (Figure 6D). DEX treatment substantially blocked the recruitment of both these inflammatory cell populations to the lung.

\section{Multiplex Software Analysis}

Next, we converted the respiratory and inflammatory cell data set to a heat map to allow for a comprehensive unbiased analysis. We chose to examine the data from 50 $\mathrm{mg} / \mathrm{ml}$ of methacholine exposure because the differences between groups were the largest for this measurement. First, the raw values for RR, TV, MV, Ti, Te, PIF, PEF, Penh, BAL neutrophils, macrophages, lymphocytes, eosinophils, and many other respiratory parameters were subjected to z-score transformation. This normalization was necessary because of the vastly different numeric scales of the various values recorded. For instance, RR (with values in the hundreds) would overwhelm Ti (with values in the fractions of seconds) on a heat map. Once z-score normalization was complete, the data from each group were averaged and converted into a heat map by TM4-MEV (freeware, see methods for details). Initially, the data set contained 23 discrete data sets. Significance analysis for microarray pared this data down to only those parameters which significantly affected the separation of experimental groups. The BAL cell data were removed for separate analysis and the significant respiratory parameters were subjected to further analysis. Hierarchal
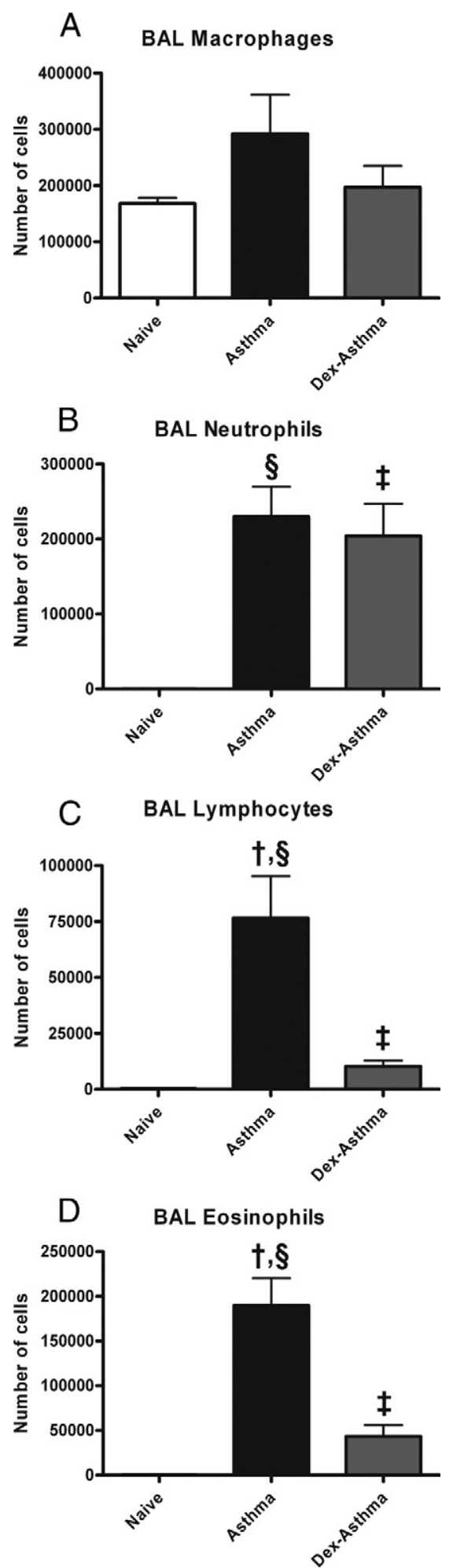

Figure 6. Bronchoalveolar (BAL) cells recovered. Each value represents the total number of cells recovered 24 hours after final allergen challenge. The data are the mean \pm SEM for $n=8 .{ }^{\dagger} P<0.05$ for Asthma compared to Dex-Asthma compared to Naïve. ${ }^{\ddagger} P<0.05$ for Dex-Asthma compared to Naive. ${ }^{\circledR} P<0.05$ for Asthma compared to Naïve. A: Numbers of macrophages. Both the Asthma and Dex-Asthma mice had significantly higher BAL neutrophil (B), lymphocyte (C), and eosinophil (D) counts compared to the Naïve mice. Additionally, the Asthma group of mice exhibited significantly elevated BAL lymphocyte $(\mathbf{C})$ and eosinophil (D) numbers compared to Dex-Asthma. 


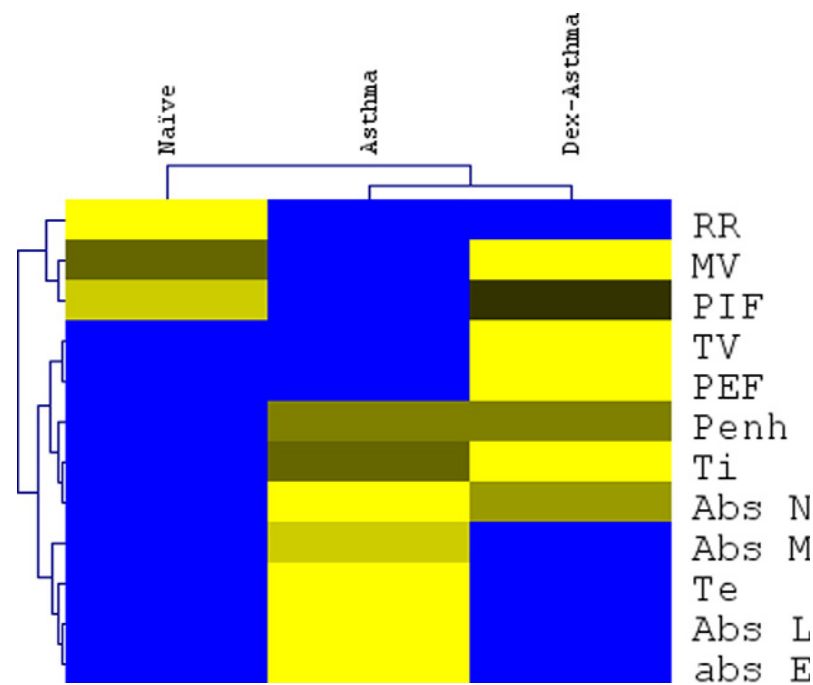

Figure 7. Heat map analyzing entire data set. The respiratory parameters and BAL cells examined previously were subjected to z-score normalization, averaged, and converted to a heat map. This presentation allows for the patterns present in the data to be examined as a whole. The data were subjected to hierarchal clustering by group and by parameter to make the patterns more evident. The grouping showed that although the Dex-Asthma respiratory parameters were similar to those of the Asthma mice, the DEX treated animals shared many common features with the healthy, Naïve animals.

clustering was performed based on group and parameter to further simplify the readout. The final product shows the trends in a single informative diagram (Figure 7). In an unbiased analysis, three discrete groups were differentiated, Naïve, Asthma, and Dex-asthma.

\section{Airways Mucus Histological Analysis}

Analysis of the respiratory physiology data clustered in the heatmap suggested that an obstruction in the asthmatic mice was improved by DEX treatment. To assess the possibility that excess mucus production could be the factor most strongly targeted by DEX we examined lung histological sections for mucus with PAS staining. As anticipated, the Naïve mice displayed very low levels of mucus production (Figure 8A). The Asthma mice (Figure $8 \mathrm{~B})$ showed markedly elevated mucus staining as compared to the Naïve and Dex-Asthma mice (Figure $8 \mathrm{C}$ ). Computer aided morphometry of the PAS staining confirmed that the Asthma mice have significantly greater

\section{Lung Mucus (PAS) Staining Area}

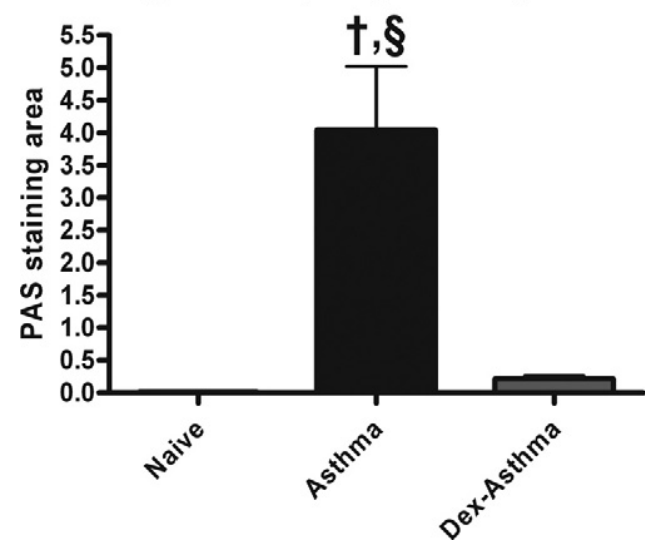

Figure 9. Computer-aided morphometry of PAS area staining. Quantitation of PAS staining area in whole lung sections of Naïve, Asthma, and DexAsthma mice show significantly elevated mucus production in Asthma mice and very little PAS intensity in Dex-Asthma and Naïve mice. Each value is the mean \pm SEM for $n=8 .{ }^{\dagger} P<0.05$ for Asthma compared to Dex-Asthma. ${ }^{\mathbb{S}} P<$ 0.05 for Asthma compared to Naive. The Asthma mice had significantly elevated lung mucus levels compared to both the Dex-Asthma and Naïve groups.

amounts of mucus as compared to the Naïve and DexAsthma mice (Figure 9).

\section{Discussion}

Significant controversy surrounds the validity of various respiratory parameters obtained from WBP devices. ${ }^{21,29,30}$ Specifically, there is concern that the data produced are indirect derivations of actual values (ie, tidal volume) which may not be accurate. Our studies were not designed to validate the accuracy of WBP. Rather, this study seeks to show that parameters recorded by WBP can be used to gain insight into the respiratory health of experimental animals and use this information to direct additional studies. Previous work has shown that WBP is a valid means of assessing pulmonary function in conscious mice even though it is less sensitive than direct measurement techniques. ${ }^{31}$ We sought to expand on this research to more fully determine the potential of WBP as a probe for respiratory health in mice. We chose to examine the respiratory health of the mice 24 hours after the final allergen challenge. Previous experimentation has revealed that at this time point, pulmonary inflammation

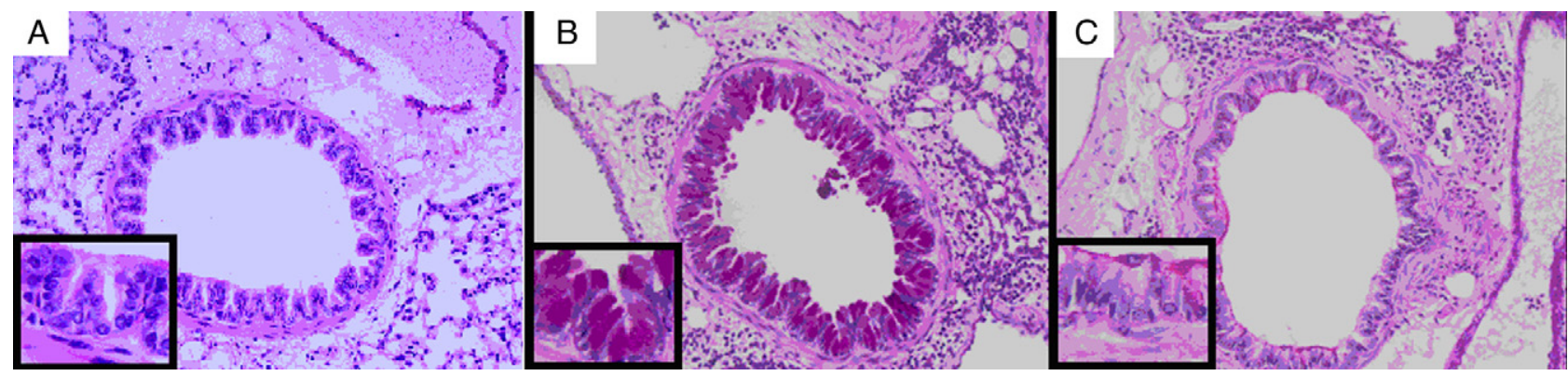

Figure 8. Photomicrographs of lungs 24 hours after final allergen challenge. PAS and H\&E stained lung sections at $20 \times$ in Naïve mice (A) show little to no mucus staining. Asthma mice show significant mucus staining (B), while the Dex-Asthma mice had near normal levels of mucus (C). Insets show ( $2 \times)$ magnified views of the respective panels. The Asthma mice had significant mucus production in the airways while the Dex-Asthma and Naïve mice had relatively low mucus levels. 
has begun to resolve so that the mice no longer exhibit elevated baseline Penh values but will still respond strongly to methacholine stimulation similar to a patient with stable asthma. The methacholine challenge allowed differentiation between the Asthma and the Dex-Asthma groups to focus the studies.

We used microarray software to aid in the analysis of our respiratory and inflammatory data sets. We used this tool to analyze most of the dozens of respiratory parameters generated by the WBP. This allowed us to statistically analyze and simplify the data in an unsupervised manner and simplified the identification of salient patterns. We believe that this technique has significant merit in the analysis of nongenetic data sets in that can significantly reduce the time and effort of data analysis while aiding the recognition of more complex patterns. Indeed, many groups have begun to see the potential of microarray software in the exploration of nongene-based data. ${ }^{32-34}$ To our knowledge this research represents the first use of heat maps to analyze and combination of respiratory and cytokine/chemokine data.

Cockroach allergen sensitization and challenge induces robust pulmonary inflammation in mice. 6,7,35,36 Our results parallel those of Campbell et $\mathrm{al}^{7}$ in that we observed significant accumulation of eosinophils, neutrophils and lymphocytes in the airways, a space normally populated solely by macrophages such that the presence of inflammatory cells indicates a pathological process. Corticosteroids are an integral component of the standard asthma controller therapies and have been widely used for decades. ${ }^{37}$ Previous research has shown that DEX is an effective treatment for mouse models of inflammatory pulmonary disease. ${ }^{36,38,39}$ Narala et $\mathrm{al}^{38}$ compared pioglitazone to dexamethasone treatment in a CRA induced model of asthma and showed that these agents were equally effective at reducing airways resistance and lung mucus production. Therefore we expected that DEX would have a large effect on the inflammatory profile in our model of allergic pulmonary inflammation. The Asthma and Dex-Asthma mice demonstrated significantly elevated eosinophils, neutrophils, and lymphocytes as compared to the Naive. However, in the Dex-Asthma mice, eosinophil and lymphocyte levels were meaningfully lower than in the Asthma group while neutrophil numbers were equivalent (Figure 6). These data can be explained since dexamethasone is a potent agent with broad effects on the inflammatory cascade and immune cell activation. The differential effects of DEX on the presence of inflammatory cells may be partially explained by DEX inhibition of apoptosis in neutrophils while promoting the controlled death of lymphocytes and eosinophils. ${ }^{40}$

The Dex-Asthma mice showed significant improvement in several respiratory parameters which are relevant to overall pulmonary health. Previous research has corroborated our results using budesonide treatment in an OVA induced model of asthma. ${ }^{41}$ These researchers noted significant constriction of the flow-volume loop in their asthmatic mice with increasing Mch challenge indicating decreased tidal volume as well as minute ventilation. Conversely, the flow-volume loops of budesonide treated asthmatic mice did not significantly differ from naïve mice on exposure to Mch. However, this research was performed in cannulated, anesthetized mice while our experiments were in conscious free-breathing animals. We observed similar effects in that DEX treatment prevented the significant decreases in TV and MV observed in the Asthma group of mice. In addition the Dex-Asthma mice exhibited supernormal MV and TV as compared to Naïve mice. In light of the previous budesonide experiments, this "overcompensation" by the DexAsthma mice is likely a voluntary response to Mch challenge and respiratory distress.

Minute ventilation reflects the degree of air exchange and in mice lung inflammation will reduce MV, as compared to healthy animals. ${ }^{42}$ Therapeutic intervention with DEX reversed this effect and increased MV in mice. It has been noted that high tidal volumes and minute ventilations antagonize the development of Mch induced bronchoconstriction in mice and humans. ${ }^{43}$ Namely, the maintenance of high tidal respiration (which in turn increases minute ventilation) curbs AHR and leads to improved respiratory functioning. It has also been established that airways resistance in mice is dependent on tidal volume. ${ }^{44}$ As tidal volume increases, lung resistance decreases due to airway-parenchymal interdependence. Briefly this phenomenon is a tethering-like effect in which the connections of the lung tissue to the airways dynamically pull the airways open. ${ }^{45}$ Considering the data it is clear that DEX treatment had strong beneficial effect on respiratory health of the experimental animals. The DexAsthma mice exhibited elevated tidal volume and therefore minute ventilation which led to decreased airways constriction and resistance. The Asthma mice in contrast were unable to compensate in the same manner and displayed low TV and MV and were therefore unable to use the above mechanism to decrease bronchoconstriction and lower airways resistance.

However, high minute ventilations are not beneficial in all situations, but the ability to significantly elevate MV during times of respiratory distress can prevent the development of dangerous sequelae such as respiratory exhaustion and hypoxia. Indeed, the most severe asthmatics enter a hypoxic-hypercapnic state which renders them relatively insensitive to ventilatory signals and as a result their minute ventilation decreases, worsening hypoxia, and hypercapnia. ${ }^{46}$ Considering the length of the experiment, it is unlikely that this mechanism effects the minute ventilation of experimental mice, as the recording period for respiratory parameters is not sufficient for appreciable hypoxia to develop.

The Dex-Asthma mice showed significant increases in PEF compared to the Asthma mice. This indicates that an expiratory obstruction present in the Asthma mice has been improved by the DEX treatment allowing for more forceful and hence rapid expulsion of air. PEF measurements in humans are the result of a voluntary maximal expiratory effort delivered to a spirometer. In humans peak expiratory flow is used to monitor asthmatics and may be measured following controlled methacholine challenge to determine the severity of the disease. Decreases of PEF to $25 \%$ below baseline are considered 
significant. ${ }^{46,47}$ Obviously, mice cannot be instructed to provide a maximal expiration and so the parameter reflects the peak flow of a tidal expiration. In murine models of lung inflammation decreases in PEF reflect increasing respiratory distress. ${ }^{48}$ Therefore, in this model, the increase in PEF seen with increasing Mch challenge in the Dex-Asthma mice is a beneficial compensation to a respiratory insult. This adaptation allows the Dex-Asthma mice to more rapidly exhale volumes of air and thus maintain an elevated TV and MV compared to the Asthma mice. The Naîve mice conversely did not show a methacholine response in PEF because they did not struggle to exhale large quantities of air to maintain MV. The Naiive mice had significantly lower levels of airways obstruction as evidenced by Te, Penh, and mucus histological analysis and so were able to maintain adequate air exchange without forceful respiratory cycles. However, if the Naïve mice could deliver a maximal expiration, it is likely that they would exhibit better peak flow similar to the Asthma and Dex-Asthma mice.

The MV and PEF improvements noted in the DexAsthma mice, as well as other differences in the respiratory data, suggest that an expiratory obstruction is being substantially ameliorated by DEX treatment. After considering the data and examining the overall patterns in the heat map diagram we hypothesized that this obstruction was due principally to airways mucus. Elevated mucus production is a hallmark of severe asthma present in human patients as well as in mouse models of pulmonary inflammation. ${ }^{49-51}$ Furthermore, treatment with glucocorticoids is known to reduce hypersecretion by goblet cells in both human asthma and murine pulmonary inflammation. ${ }^{36,52,53}$ Histological analysis revealed that the Asthma mice had significantly elevated mucus as compared to the Nairve group. Conversely, the Dex-Asthma mice showed a significant reduction in mucus levels compared to the Asthma mice. This indicates that the DEX treatment was successful in reducing the amount of mucus to near Naîve levels and is a likely candidate for the respiratory improvement seen in the DexAsthma mice.

Finally, we examined the Penh values of the experimental animals. Penh is used in WBP experiments both as a screening parameter for pulmonary inflammation and as an estimate of airways resistance. Interestingly, in this case, examination of Penh alone would not have accurately represented the relative respiratory fitness of the experimental animals. Namely, both the Asthma and Dex-Asthma mice had equivalently elevated Penh values at the higher dose of Mch. However, as shown in the current analysis, their relative respiratory health differs to a large degree. This difference can be explained because there are multiple parameters contributing to the elevation in the Penh values of the Asthma and DexAsthma animals. In the Asthma mice, the increase in Penh is driven primarily by the significantly elevated Te. Conversely, in the Dex-Asthma mice, Penh is affected most strongly by the significant increase in PEF values. These data indicate that relying only on the Penh will obscure important changes that may appropriately direct additional studies. In the current study, WBP suggested possible changes in the amount of airways mucus which was later confirmed by histology.

In conclusion, this study suggests that WBP respiratory parameters, other than Penh, contain useful information about the respiratory health of experimental animals. We were able to demonstrate that anti-inflammatory treatment was able to induce significant changes in this data. Furthermore, these changes allowed us to predict that mucus levels in the airways were the most likely source of the respiratory differences observed between the experimental groups. Therefore, we believe that WBP can provide significant and applicable insight into the pulmonary fitness of mice even though it cannot probe true respiratory mechanics.

\section{Acknowledgment}

We thank Marc Lenburg, Ph.D., for helpful discussions regarding the statistical analysis.

\section{References}

1. Zosky GR, Sly PD: Animal models of asthma. Clin Exp Allergy 2007 37:973-988

2. Darcan-Nicolaisen $Y$, Meinicke H, Fels G, Hegend O, Haberland A, Kuhl A, Loddenkemper C, Witzenrath M, Kube S, Henke W, Hamelmann E: Small interfering RNA against transcription factor STAT6 inhibits allergic airway inflammation and hyperreactivity in mice. J Immunol 2009, 182:7501-7508

3. Kang NI, Yoon HY, Lee YR, Won M, Chung MJ, Park JW, Hur GM, Lee HK, Park BH: A20 attenuates allergic airway inflammation in mice. J Immunol 2009, 183:1488-1495

4. Mabalirajan U, Dinda AK, Sharma SK, Ghosh B: Esculetin restores mitochondrial dysfunction and reduces allergic asthma features in experimental murine model. J Immunol 2009, 183:2059-2067

5. Melgert BN, Oriss TB, Qi Z, Dixon-McCarthy B, Geerlings M, Hylkema MN, Ray A: Macrophages: regulators of sex differences in asthma? Am J Respir Cell Mol Biol 2009, 42:595-603

6. Mckinley L, Kim J, Bolgos GL, Siddiqui J, Remick DG: Reproducibility of a novel model of murine asthma-like pulmonary inflammation. Clin Exp Immunol 2004, 136:224-231

7. Campbell EM, Kunkel SL, Strieter RM, Lukacs NW: Temporal role of chemokines in a murine model of cockroach allergen-induced airway hyperreactivity and eosinophilia. J Immunol 1998, 161:7047-7053

8. Gueders MM, Paulissen G, Crahay C, Quesada-Calvo F, Hacha J, Van Hove C, Tournoy K, Louis R, Foidart JM, Noel A, Cataldo DD: Mouse models of asthma: a comparison between C57BL/6 and $B A L B / c$ strains regarding bronchial responsiveness, inflammation, and cytokine production. Inflamm Res 2009, 58:845-854

9. Nadeem A, Fan M, Ansari HR, Ledent C, Mustafa SJ: Enhanced airway reactivity and inflammation in $A(2 A)$ adenosine receptor-deficient allergic mice. Am J Physiol-Lung Cell Mol Physiol 2007, 292:L1335-L1344

10. Stowell NC, Seideman J, Raymond HA, Smalley KA, Lamb RJ, Egenolf DD, Bugelski PJ, Murray LA, Marsters PA, Bunting RA, Flavell RA, Alexopoulou L, San Mateo LR, Griswold DE, Sarisky RT, Mbow ML, Das AM: Long-term activation of TLR3 by poly(l:C) induces inflammation and impairs lung function in mice. Respir Res 2009, 10:43

11. Campbell JD, Buckland KF, McMillan SJ, Kearley J, Oldfield WLG, Stern LJ, Gronlund H, van Hage M, Reynolds CJ, Boyton RJ, Cobbold SP, Kay AB, Altmann DM, Lloyd CM, Larche M: Peptide immunotherapy in allergic asthma generates IL-10-dependent immunological tolerance associated with linked epitope suppression. J Exp Med 2009, 206:1535-1547

12. Oldenburg PJ, Wyatt TA, Factor PH, Sisson JH: Alcohol feeding 
blocks methacholine-induced airway responsiveness in mice. Am $J$ Physiol Lung Cell Mol Physiol 2009, 296:L109-L114

13. Bartlett NW, Walton RP, Edwards MR, Aniscenko J, Caramori G, Zhu J, Glanville N, Choy KJ, Jourdan P, Burnet J, Tuthill TJ, Pedrick MS, Hurle MJ, Plumpton C, Sharp NA, Bussell JN, Swallow DM, Schwarze J, Guy B, WAlmond J, Jeffery PK, Lloyd CM, Papi A, Killington RA, Rowlands DJ, Blair ED, Clarke NJ, Johnston SL: Mouse models of rhinovirus-induced disease and exacerbation of allergic airway inflammation. Nat Med 2008, 14:199-204

14. Hamelmann E, Schwarze J, Takeda K, Oshiba A, Larsen GL, Irvin CG, Gelfand EW: Noninvasive measurement of airway responsiveness in allergic mice using barometric plethysmography. Am J Resp Crit Care Med 1997, 156:766-775

15. Lomask M: Further exploration of the Penh parameter. Exp Toxicol Path 2006, 57:13-20

16. DeLorme MP, Moss OR: Pulmonary function assessment by wholebody plethysmography in restrained versus unrestrained mice. J Pharmacol Toxicol Methods 2002, 47:1-10

17. Nishiuma T, Nishimura Y, Okada T, Kuramoto E, Kotani Y, Jahangeer S, Nakamura S: Inhalation of sphingosine kinase inhibitor attenuates airway inflammation in asthmatic mouse model. Am J Physiol-Lung Cell Mol Physiol 2008, 294:L1085-L1093

18. Bates J, Irvin C, Brusasco V, Drazen J, Fredberg J, Loring S, Eidelman D, Ludwig M, Macklem P, Martin J, Hantos Z, Hyatt R, Lai-Fook S, Leff A, Solway J, Lutchen K, Suki B, Mitzner W, Pare P, Pride N, Sly P: The use and misuse of Penh in animal models of lung disease. Am J Resp Cell Mol Biol 2004, 31:373-374

19. Hantos Z, Brusasco V: Assessment of respiratory mechanics in small animals: the simpler the better? J Appl Physiol 2002, 93:1196-1197

20. Lundblad LKA, Adler A, Irvin CG, Bates JHT: Interpreting Penh in mice-reply. J Appl Physiol 2003, 94:831-832

21. Mitzner W: Why can't mice just learn to pant? J Appl Physiol 2008, 105:402-402

22. Gavett SH, O'Hearn DJ, Li X, Huang SK, Finkelman FD, Wills-Karp M: Interleukin 12 inhibits antigen-induced airway hyperresponsiveness, inflammation, and Th2 cytokine expression in mice. J Exp Med 1995, 182:1527-1536

23. Levitt RC, Mitzner W: Expression of airway hyperreactivity to acetylcholine as a simple autosomal recessive trait in mice. FASEB J 1988 , 2:2605-2608

24. Tankersley CG, Fitzgerald RS, Levitt RC, Mitzner WA, Ewart SL, Kleeberger SR: Genetic control of differential baseline breathing pattern. J Appl Physiol 1997, 82:874-881

25. Rudolf CD: Rudolf's Pediatrics. McGraw Hill, Columbus $\mathrm{OH}$ 2002, p. 277

26. Hoshino Y, Ayuse T, Kurata S, Schneider H, Kirkness JP, Patil SP, Schwartz AR, Oi K: The compensatory responses to upper airway obstruction in normal subjects under propofol anesthesia. Respir Physiol Neurobiol 2009, 166:24-31

27. Tantucci C, Ellaffi M, Duguet A, Zelter M, Similowski T, Derenne JP, Milic-Emili J: Dynamic hyperinflation and flow limitation during methacholine-induced bronchoconstriction in asthma. Eur Respir J 1999 14:295-301

28. Baydur A, Wilkinson L, Mehdian R, Bains B, Milic-Emili J: Extrathoracic expiratory flow limitation in obesity and obstructive and restrictive disorders: effects of increasing negative expiratory pressure. Chest 2004, 125:98-105

29. Adler A, Cieslewicz G, Irvin CG: Unrestrained plethysmography is an unreliable measure of airway responsiveness in BALB/c and C57BL/6 mice. J Appl Physiol 2004, 97:286-292

30. Lundblad LKA, Irvin CG, Adler A, Bates JHT: A reevaluation of the validity of unrestrained plethysmography in mice. J Appl Physiol 2002, 93:1198-1207

31. Glaab T, Ziegert M, Baelder R, Korolewitz R, Braun A, Hohlfeld JM, Mitzner W, Krug N, Hoymann HG: Invasive versus noninvasive measurement of allergic and cholinergic airway responsiveness in mice. Respir Res 2005, 6:139

32. Finnerty CC, Przkora R, Herndon DN, Jeschke MG: Cytokine expression profile over time in burned mice. Cytokine 2009, 45:20-25

33. Hsu HY, Wittemann S, Schneider EM, Weiss M, Joos TO: Suspension microarrays for the identification of the response patterns in hyperinflammatory diseases. Med Eng Phys 2008, 30:976-983
34. Roberts L, Passmore JA, Williamson C, Little F, Bebell LM, Mlisana K, Burgers WA, van Loggerenberg F, Walzl G, Siawaya JF, Karim QA, Karim SS: Plasma cytokine levels during acute HIV-1 infection predict HIV disease progression. AIDS 24:819-831

35. Page K, Lierl KM, Hughes VS, Zhou P, Ledford JR, Wills-Karp M: TLR2-mediated activation of neutrophils in response to German cockroach frass. J Immunol 2008, 180:6317-6324

36. Kim J, McKinley L, Siddiqui J, Bolgos GL, Remick DG: Prevention and reversal of pulmonary inflammation and airway hyperresponsiveness by dexamethasone treatment in a murine model of asthma induced by house dust. Am J Physiol Lung Cell Mol Physiol 2004, 287:L503-L509

37. National Heart Lung and Blood Institute: Guidelines for the diagnosis and management of asthma, 2007 Bethesda Maryland, National Institutes of Health, pp. 28-52

38. Narala VR, Ranga R, Smith MR, Berlin AA, Standiford TJ, Lukacs NW, Reddy RC: Pioglitazone is as effective as dexamethasone in a cockroach allergen-induced murine model of asthma. Respir Res 2007, 8:90

39. Kumar RK, Herbert C, Thomas PS, Wollin L, Beume R, Yang M, Webb DC, Foster PS: Inhibition of inflammation and remodeling by roflumilast and dexamethasone in murine chronic asthma. J Pharmacol Exp Ther 2003, 307:349-355

40. Sivertson KL, Seeds MC, Long DL, Peachman KK, Bass DA: The differential effect of dexamethasone on granulocyte apoptosis involves stabilization of $\mathrm{Mcl}-1 \mathrm{~L}$ in neutrophils but not in eosinophils. Cell Immunol 2007, 246:34-45

41. Gong PH, Gao ZC, Hu P, Xu Y: Investigation of the measurement of murine airway hyperresponsiveness and the therapeutic effects of budesonide on ovalbumin sensitized and challenged mice. Chin Med J (Engl) 2005, 118:1959-1964

42. de Hennezel L, Debarre S, Ramisse F, Delamanche S, Harf A, Alonso $\mathrm{JM}$, Calvet JH: Plethysmography for the assessment of pneumococcal pneumonia and passive immunotherapy in a mouse model. Eur Respir J 2001, 17:94-99

43. Chen B, Liu G, Shardonofsky F, Dowell M, Lakser O, Mitchell RW, Fredberg JJ, Pinto LH, Solway J: Tidal breathing pattern differentially antagonizes bronchoconstriction in C57BL/6J vs. A/J mice. J Appl Physiol 2006, 101:249-255

44. Kips JC, Anderson GP, Fredberg JJ, Herz U, Inman MD, Jordana M, Kemeny DM, Lotvall J, Pauwels RA, Plopper CG, Schmidt D, Sterk PJ, Van Oosterhout AJ, Vargaftig BB, Chung KF: Murine models of asthma. Eur Respir J 2003, 22:374-382

45. Adler A, Cowley EA, Bates JH, Eidelman DH: Airway-parenchymal interdependence after airway contraction in rat lung explants. J Appl Physiol 1998, 85:231-237

46. Eckert DJ, Catcheside PG, Smith JH, Frith PA, McEvoy RD: Hypoxia suppresses symptom perception in asthma. Am J Respir Crit Care Med 2004, 169:1224-1230

47. Mansell AL, Walders N, Wamboldt MZ, Carter R, Steele DW, Devin JA, Monica TH, Miller AL, Wamboldt FS: Effect of body mass index on response to methacholine bronchial provocation in healthy and asthmatic adolescents. Pediatr Pulmonol 2006, 41:434-440

48. Li YT, He B, Wang YZ, Wang J: Effects of intratracheal administration of nuclear factor-kappaB decoy oligodeoxynucleotides on long-term cigarette smoke-induced lung inflammation and pathology in mice. Respir Res 2009, 10:79

49. Barnes PJ: Pathophysiology of asthma. Br J Clin Pharmacol 1996, 42:3-10

50. Vasconcelos JF, Teixeira MM, Barbosa-Filho JM, Agra MF, Nunes XP Giulietti AM, Ribeiro-Dos-Santos R, Soares MB: Effects of umbelliferone in a murine model of allergic airway inflammation. Eur $\mathrm{J}$ Pharmacol 2009, 609:126-131

51. Wu CA, Peluso JJ, Shanley JD, Puddington L, Thrall RS: Murine cytomegalovirus influences Foxj1 expression, ciliogenesis, and mucus plugging in mice with allergic airway disease. Am J Pathol 2008, 172:714-724

52. McMillan SJ, Xanthou G, Lloyd CM: Therapeutic administration of Budesonide ameliorates allergen-induced airway remodelling. Clin Exp Allergy 2005, 35:388-396

53. Rogers DF, Barnes PJ: Treatment of airway mucus hypersecretion. Ann Med 2006, 38:116-125 